All who are in any way connected with hospitals will appreciate that there is still much cause for dissatisfaction in the field of nutrition. The training of suitable staff and the recognition of their status must be relentlessly pursued if success is to be achieved. All the same, it is true to say that nutrition, with its many practical applications, has become a vital factor in hospital catering, and that fact must justify the hope that hospitals will in time lead the way in food education.

\title{
The Teaching of Nutrition : A Summary
}

\section{By John YudкIn, Queen Elizabeth College, London, W.8}

To-day's proceedings have shown that nutrition education can take place at three levels. The first is as an essential part of general education in living by the universal inculcation of sound nutritional habits. The second is in teaching nutrition for crafts and professions concerned in applying nutritional knowledge in practice, cooks, caterers, agriculturalists, doctors and particularly dietitians. The third is in the training of professional nutritionists.

We have seen that the first problem is mainly the concern of the school teacher. In so far as there is nowadays an extensive school meals service, it is possible to give, mainly by example, practical guidance in the establishment of sound nutritional habits and even to use the opportunity to teach elementary nutritional principles. The fact that such teaching is continued in later school life in association with the teaching of housecraft, however, means that the older boys are not influenced in the same way as the girls. The question of filling the gap might well be considered by those responsible for the teaching of nutrition in schools.

In most of the discussion on the teaching of nutrition as part of a craft or profession it has generally been agreed that the best way is to include it as part of the practical training and not as a separate subject. Cooks and caterers should be taught nutrition while being taught the handling and preparation of food; doctors should receive nutritional instruction in the wards and clinics. The difficulty, however, is that at present those who teach nutrition are themselves not sufficiently well trained in the subject. There is thus, for example, a tendency for domestic science teachers to learn their nutrition from other domestic science teachers, so that there is inevitably a perpetuation of ill-founded, inaccurate and out-of-date information from generation to generation.

Similarly, medical students, if taught nutrition at all, will be taught by the few clinicians who have an interest in the subject but whose own knowledge, to judge from letters in the medical journals, is not always necessarily sound. Again, as we have heard, students in technical schools can learn either from experts in the crafts of food preparation or food technology, who have little nutritional training, or from academically minded chemists or biologists, who may not have the ability to implant essential nutritional information at an appropriate non-academic level. 
The obvious question arises, 'Who is to teach the teachers ?' It seems clear that the need is for the training of nutritionists having, on the one hand, a sound academic background and, on the other, a full appreciation that nutrition is concerned with what people eat. As well as providing the source from which can be drawn the teachers in nutrition at all levels, the existence of trained nutritionists might well in time influence those with administrative responsibility to realize the significance of the science of nutrition. It should gradually produce those changes to which our discussion has drawn attention, changes in attitude of the housecraft teacher, who so often has little use for nutrition, changes in the armed services, where nutrition is still regarded as a minor and somewhat theoretical part of hygiene or pathology, changes above all in the attitude of mind of those authorities who seem mostly responsible for the inadequate number of dietitians.

It is from this point of view that we may look upon the courses for the new degree in nutrition. Taught to appreciate that nutrition is concerned with all aspects of food production, preparation and consumption, graduates in nutrition should not only provide the future teachers of nutrition, but might well be expected to produce a new attitude to nutrition in those who are ultimately responsible in so many ways for feeding us and our fellow human beings. 